\title{
Mechanical and Morphological Properties of Poly-3-hydroxybutyrate/Poly(butyleneadipate-co-terephthalate)/ Layered Double Hydroxide Nanocomposites
}

\author{
Yen Leng Pak, ${ }^{1}$ Mansor Bin Ahmad, ${ }^{1}$ Kamyar Shameli, ${ }^{1,2}$ Wan Md Zin Wan Yunus, ${ }^{3}$ \\ Nor Azowa Ibrahim, ${ }^{1}$ and Norhazlin Zainuddin ${ }^{1}$ \\ ${ }^{1}$ Department of Chemistry, Faculty of Science, Universiti Putra Malaysia, 43400 Serdang, Selangor, Malaysia \\ ${ }^{2}$ Nanotechnology and Advance Department, Materials and Energy Research Center, Meshkin-Dasht Road, \\ Karaj 3177983634, Iran \\ ${ }^{3}$ Faculty of Defence Science and Technology, National Defence University of Malaysia, Sungai Besi Camp, \\ 57000 Kuala Lumpur, Malaysia
}

Correspondence should be addressed to Mansor Bin Ahmad; mansorahmad@gmail.com and Kamyar Shameli; kamyarshameli@gmail.com

Received 1 September 2013; Revised 1 November 2013; Accepted 5 November 2013

Academic Editor: Haiqiang Wang

Copyright (C) 2013 Yen Leng Pak et al. This is an open access article distributed under the Creative Commons Attribution License, which permits unrestricted use, distribution, and reproduction in any medium, provided the original work is properly cited.

\begin{abstract}
Nanocomposites of poly-3-hydroxybutyrate/poly(butyleneadipate-co-terephthalate)/layered double hydroxide (PHB/PBAT/LDH) were prepared from a binary blend of $\mathrm{PHB} / \mathrm{PBAT}$ and stearate- $\mathrm{Zn}_{3} \mathrm{Al} \mathrm{LDH}$ via a solution casting method using chloroform as solvent in this study. The pristine $\mathrm{Zn}_{3} \mathrm{Al} \mathrm{LDH}$ was synthesized from nitrate salts solution at $\mathrm{pH} 7$ by using coprecipitation technique and then was modified by stearate anions surfactant via ion exchange reaction. As a result, the basal spacing of the LDH was increased from 8.77 to $24.94 \AA$ after the modification. Intercalated nanocomposites were formed due to the presence of diffraction peak in XRD diffractograms. The infrared spectrum of stearate- $\mathrm{Zn}_{3} \mathrm{Al} \mathrm{LDH}$ exhibited the existence of stearate anions in the synthesized $\mathrm{Zn}_{3} \mathrm{Al} \mathrm{LDH}$. Mechanical properties with $2 \mathrm{wt} \%$ stearate- $\mathrm{Zn}_{3} \mathrm{Al} \mathrm{LDH}$ loading nanocomposites showed $56 \mathrm{wt} \%$ improvements in elongation at break compared to those of the blend.
\end{abstract}

\section{Introduction}

Great contributions have been made by introducing polymers into the market to enhance the grade of living and lifestyle. Plastics are being used throughout the world. Plastics are extremely important to the job market especially packaging field. Production of ecofriendly plastics that are more compatible with the environment is needed since plastics created ecological concern due to the lack of deprivation. Therefore, biodegradable plastics began being of sparking interest. Creating of biodegradable materials draw high attention as oil prices increased and they are considered to assist in reducing the waste issue.
Poly-3-hydroxybutyrate (PHB) is produced by controlled bacterial fermentation [1]. It is a high melting temperature and a high degree of crystallinity of semicrystalline polymer. It is not soluble in water and $100 \%$ biodegraded. PHB has a few points of weakness that limited its applications such as inefficient and high cost of the fermentation and extraction process, poor mechanical properties, and poor formability. Cracking and brittleness properties of PHB are because of the large spherulites in its structure. Efforts have been made by worldwide researchers to overcome those problems and to improve different properties. The most cost effective and generally used method is blending of PHB with another kind of polymers, [2-5] such as starch, polycaprolactone (PCL), 
poly (vinyl acetate) (PVAc), and cellulose derivatives which have been studied to modify the properties and expand its practical application [6-8].

Poly (butylene adipate-co-terephthalate) (PBAT) is ecofriendly polymers which totally biodegraded with the assist of naturally occurring enzymes in a few weeks. It has the same properties as low density polyethylene (LDPE), but with superior mechanical properties. Its excellent physical properties give high flexibility when blended with other biodegradable resins. As a result, PBAT is an excellent candidate for toughening polymers such as poly (lactic acid) and PHBV [9].

Inorganic-organic nanocomposite materials with functional organic compounds immobilized into a layered inorganic matrix have a potential to offer scientific and technological advantages since the organized two-dimensional arrays of organic species between the interlayers can result in novel functions that are different from the typical functions of the individual organic species [10-17].

An electrostatic layer-by-layer assembly technique that employs inorganic nanocomposites as building blocks is a possible means of forming a well-ordered multilayered architecture containing the arrays because the nanocomposites have ultimate two-dimensional anisotropy with nanoscale thickness and microscale length in the plane of sheet [18]. It is known that some smectite clay minerals like montmorillonite, metal phosphates, and layered oxides can be exfoliated into negatively charged nanosheets [19]. In contrast, positively charged nanosheets are a minority among exfoliated nanosheets. Recently, the exfoliation of layered double hydroxides (LDHs) has been studied as a method of preparing such positively charged nanosheets [20]. LDH nanosheets have high potential for being used as building blocks to integrate negatively charged organic molecules into restricted arrays, due to their high stability and compatibility with many functional molecules [21-24].

Layered double hydroxide ( $\mathrm{LDH})$ is one of the attractive choices as nanofiller which have significantly improved the physicochemical properties of polymer matrix. In contrast to either neat polymer or the conventional composites, polymer nanocomposites are characterized by improved mechanical, thermal, and barrier properties, reduced gas permeability, and flame retardancy [25-28]. Improvement in properties of the nanocomposites is related to their unique phase morphology that maximizes the interfacial interaction between the well-dispersed nanometer size domains and the matrices. LDH has received world-wide attention because they are useful to be incorporated in many applications, such as catalysis, stabilizer, flame retardant materials, medical materials, adsorbents, ion exchangers, and in environmental chemistry [29].

In this research, our aims are to investigate the influences of stearate- $\mathrm{Zn}_{3} \mathrm{Al} \mathrm{LDH}$ nanolayers on the tensile properties and morphology of PHB/PBAT blends.

\section{Experimental Section}

2.1. Materials. Poly [(r)-3-hydroxybutyric acid] was purchased from Sigma-aldrich, Germany, in powder form.
Poly (butylenes adipate-co-terephthalate), PBAT, trade name ECOFLEX, F BX 7011, was supplied by BASF Plastic Technologies, USA. Zinc nitrate $\left(\mathrm{Zn}\left(\mathrm{NO}_{3}\right)_{2} \cdot 6 \mathrm{H}_{2} \mathrm{O}\right)$ was supplied by Bendosen Laboratory Chemicals, Norway. Aluminium nitrate $\left(\mathrm{Al}\left(\mathrm{NO}_{3}\right)_{3} \cdot 9 \mathrm{H}_{2} \mathrm{O}\right)$ was supplied by $\mathrm{Hmbg}$ Chemicals, Germany. All the chemicals were used as received without further purification process.

2.2. Synthesis of $Z n_{3} A l L D H$. The $Z_{3} A l L D H$ was synthesized via coprecipitation by adding dropwise a solution of $\mathrm{NaOH}(1 \mathrm{M})$ into a $250 \mathrm{~mL}$ solution of $22.30 \mathrm{~g}$ $\mathrm{Zn}\left(\mathrm{NO}_{3}\right)_{2} \cdot 6 \mathrm{H}_{2} \mathrm{O}$ and $9.38 \mathrm{~g} \mathrm{Al}\left(\mathrm{NO}_{3}\right)_{3} \cdot 9 \mathrm{H}_{2} \mathrm{O}$ with the mole ratio of $3: 1$ until $\mathrm{pH} 7$ was obtained. The solution was stirred vigorously under nitrogen atmosphere in order to minimize any contamination of carbonate from the air. At $100 \mathrm{rpm}$ and $70^{\circ} \mathrm{C}$, the resulting suspension was shaken for 16 hours. The slurry was filtered and washed several times with deionized water. The $\mathrm{Zn}_{3} \mathrm{Al} \mathrm{LDH}$ was obtained after being dried at $60^{\circ} \mathrm{C}$ for 24 hours.

2.3. Preparation of Stearate $-\mathrm{Zn}_{3} \mathrm{Al} L D H$. The stearate- $\mathrm{Zn}_{3} \mathrm{Al}$ $\mathrm{LDH}$ was prepared by replacing nitrate ions in the $\mathrm{LDH}$ layers with stearate ions using the following method. One gram of dry $\mathrm{Zn}_{3} \mathrm{Al} \mathrm{LDH}$ was dispersed into $1 \mathrm{~L}$ of $0.003 \mathrm{M}$ sodium stearate solution. The solution was stirred for 24 hours and aged at $70^{\circ} \mathrm{C}$ in water bath. The slurry was filtered and washed several times with deionized water and dried at $60^{\circ} \mathrm{C}$. The dried sample was ground and sieved into particles which were less than 100 micrometer. This chemical modification method already reported by Costantino et al. [30].

2.4. Preparation of PHB/PBAT/Stearate- $Z n_{3} \mathrm{Al}$ LDH Nanocomposites. The nanocomposites of PHB/PBAT blend and stearate- $\mathrm{Zn}_{3} \mathrm{Al} \mathrm{LDH}$ were prepared by a solution casting method. The blend composition was kept constant (PHB $90 \mathrm{wt} \%$ + PBAT $30 \mathrm{wt} \%$ ) whereas the stearate- $\mathrm{Zn}_{3} \mathrm{Al} \mathrm{LDH}$ content was varied between $0 \mathrm{wt} \%$ and $5 \mathrm{wt} \%$. Desired mount of stearate- $\mathrm{Zn}_{3} \mathrm{Al} \mathrm{LDH}$ and blend were measured and transferred into $50 \mathrm{~mL}$ of choloform. Both mixtures were stirred for $1 \mathrm{~h}$, mixed, and stirred for another $1 \mathrm{~h}$. The mixture was casted in a petri dish and left in fume cupboard for few days to obtain the sample sheets.

2.5. Characterization Techniques. X-ray diffraction (XRD) measurement for LDHs and nanocomposites were carried out by using Shimadzu XRD 6000 diffractometer at $30 \mathrm{kV}$ and $30 \mathrm{~mA}$ with $\mathrm{Cu}-\mathrm{Ka}$ radiation of the wavelength of $1.5405 \mathrm{~nm}$ in $2 \theta$ range from 2 to $30^{\circ}$. Fourier-transform infrared (FTIR) spectra of the materials were recorded using a Perkin Elmer Spectrum 1000 series Spectrophotometer equipped with attenuated total reflectance (ATR). The infrared spectra of the samples were recorded in the range of frequency of 400$4,000 \mathrm{~cm}^{-1}$. Scanning electron microscopy (SEM) images were obtained using a Philips XL30 ESEM scanning electron microscope operated at $20 \mathrm{kV}$. The samples were coated with gold by a Bio-Rad coating system before viewing. Tensile tests were carried out by a Universal Testing Machine, Instron 4302, according to ASTM D638-5. The samples were cut into 
dumbbell shape and the average of thickness and width were measured. The average of at least 5 measurements of tensile test was used in calculation.

\section{Results and Discussion}

3.1. Characterization of $Z n_{3} A l L D H$ and Stearate- $Z n_{3} A l L D H$. Figure 1 illustrates the XRD patterns for the pristine and stearate- $\mathrm{Zn}_{3} \mathrm{Al} \mathrm{LDH}$ in the range of $2 \theta$ from 2 to $30^{\circ}$. Both LDHs were crystalline in nature with definite and distinct of layered structure. By using Bragg's equation, $n \lambda=2 d \times \sin \theta$, the first diffraction peak from both pristine and stearate$\mathrm{Zn}_{3} \mathrm{Al} \mathrm{LDH}$ was used to calculate the basal spacing (d). The clay interlayer spacing was increased from $8.77 \AA$ in pristine $\mathrm{LDH}$ (corresponding $2 \theta$ value of $\langle 003\rangle$ peak is $10.08^{\circ}$ ) to $24.94 \AA$ in stearate- $\mathrm{Zn}_{3} \mathrm{Al} \mathrm{LDH}\left(2 \theta=3.54^{\circ}\right)$ after the modification of pristine $\mathrm{LDH}$ with stearate ions. The increase of the basal spacing indicates that the stearate anions were intercalated into the interlayers of LDH successfully [25].

FTIR spectra of the pristine $\mathrm{Zn}_{3} \mathrm{Al} \mathrm{LDH}$ and stearate$\mathrm{Zn}_{3} \mathrm{Al} \mathrm{LDH}$ are exposed in Figure 2. The broad absorption peak observed was at around $3398 \mathrm{~cm}^{-1}$ in pristine LDH for $\mathrm{O}-\mathrm{H}$ stretching of both hydroxide layers and interlayer water molecules [26]. An intense peak observed at $1340 \mathrm{~cm}^{-1}$ is due to the asymmetric and symmetric vibration of the nitrate anions in Figure 2(a) [27]. At about $1639 \mathrm{~cm}^{-1}$, the interlayer water of stretching vibration $(\mathrm{H}-\mathrm{OH})$ can be obtained. The lattice vibration bands of the $\mathrm{M}-\mathrm{O}$ and $\mathrm{O}-\mathrm{M}-\mathrm{O}(\mathrm{M}=\mathrm{Mg}$ or $\mathrm{Al}$ ) bonding are present at below $800 \mathrm{~cm}^{-1}$ region.

At the same time, the stearate- $\mathrm{Zn}_{3} \mathrm{Al} \mathrm{LDH}$ spectrum (Figure 2(b)) shows the peak at around 2850 and $2917 \mathrm{~cm}^{-1}$ which exhibits the $\mathrm{C}-\mathrm{H}$ stretching vibration due to appearance of the $-\mathrm{CH}_{3}$ and $-\mathrm{CH}_{2}$ group in the chain of stearate anions [29]. Carboxylate asymmetric and symmetric stretching is represented by two intense absorption peaks at $1546 \mathrm{~cm}^{-1}$ and $1409 \mathrm{~cm}^{-1}$, respectively [31]. It can be concluded that spectrum of the stearate- $\mathrm{Zn}_{3} \mathrm{Al} \mathrm{LDH}$ and pristine $\mathrm{Zn}_{3} \mathrm{Al} \mathrm{LDH}$ contains many similar major peaks. Surface morphology of the pristine $\mathrm{Zn}_{3} \mathrm{Al} \mathrm{LDH}$ and modified stearate- $\mathrm{Zn}_{3} \mathrm{Al} \mathrm{LDH}$ particles are shown in Figure 3. As shown in Figure 3, the clay is received as porous particles in the existence of the organic anions [26].

\subsection{Characterization of $\mathrm{PHB} / \mathrm{PBAT} /$ Stearate $-\mathrm{Zn} \mathrm{n}_{3} \mathrm{Al} \mathrm{LDH}$.} XRD patterns for pure PHB, pure PBAT, PHB/PBAT blend, and $\mathrm{PHB} / \mathrm{PBAT} / \mathrm{LDH}$ nanocomposites are shown in Figure 4. The peaks obtained in the diffraction patterns of the pure films of PHB and PBAT also appeared in PHB/PBAT blends. The diffraction pattern of polymer blend displayed distinct peaks $(2 \theta)$ at $13.18^{\circ}, 16.48^{\circ}, 19.76^{\circ}, 21.96^{\circ}, 25.36^{\circ}$, and $26.90^{\circ}$, which correspond to the (020), (110), (101), (111), (121), and (002) reflections of the orthorhombic crystalline lattice, respectively. The diffraction peaks remain practically unchanged in $\mathrm{PHB} / \mathrm{PBAT}$ nanocomposites diffractograms can be observed. This observation suggested that the polymer blend crystalline lattice is not modified appreciably in the existence of $\mathrm{LDH}$ [32].

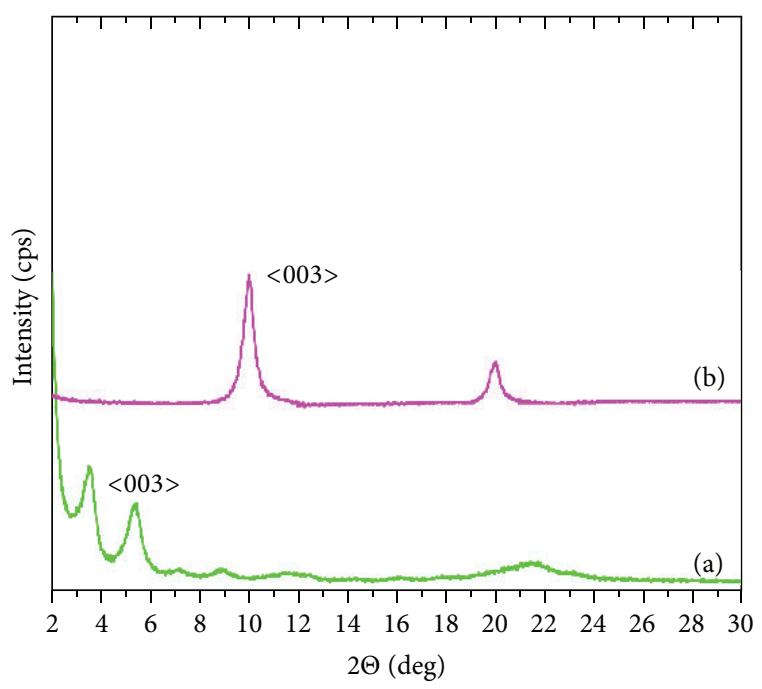

(a) $\mathrm{Zn}_{3} \mathrm{~A} 1 \mathrm{LDH}$

(b) Stearate- $\mathrm{Zn}_{3} \mathrm{Al} \mathrm{LDH}$

FIGURE 1: XRD pattern of (a) pristine $\mathrm{Zn}_{3} \mathrm{Al} \mathrm{LDH}$ and (b) stearate$\mathrm{Zn}_{3} \mathrm{Al} \mathrm{LDH}$.

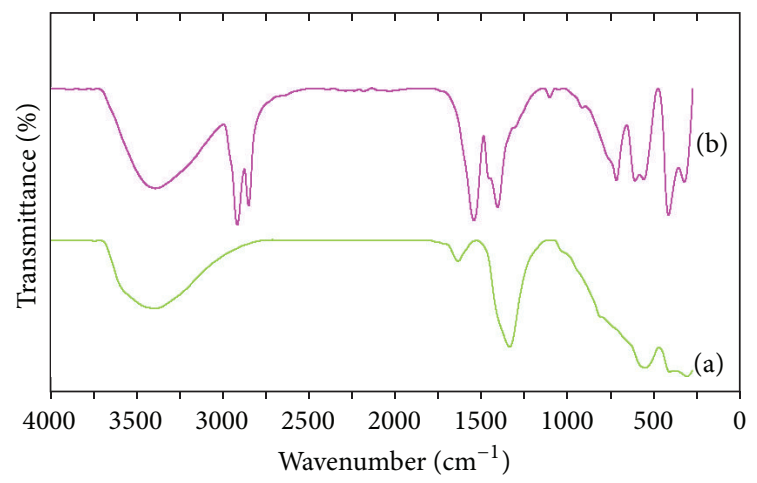

(a) $\mathrm{Zn}_{3} \mathrm{~A} 1 \mathrm{LDH}$

(b) Stearate- $\mathrm{Zn}_{3} \mathrm{~A} 1 \mathrm{LDH}$

FIGURE 2: FTIR spectra for (a) pristine $\mathrm{Zn}_{3} \mathrm{Al} \mathrm{LDH}$ and (b) stearate$\mathrm{Zn}_{3} \mathrm{Al} \mathrm{LDH}$.

The presence of the diffraction peak in the $\mathrm{PHB} /$ PBAT/LDH nanocomposites with 1.0, 2.0, 3.0, 4.0, or $5.0 \mathrm{wt} \%$ of the $\mathrm{LDH}$ indicated that the stearate- $\mathrm{Zn}_{3} \mathrm{Al} \mathrm{LDH}$ layers were completely intercalated in the blend matrix. The interlayer spacings for $1.0,2.0,3.0,4.0$, or $5.0 \mathrm{wt} \%$ of the $\mathrm{LDH}$ in polymer blend were $41.25 \AA, 43.70 \AA, 40.87 \AA$, and $40.49 \AA$, respectively.

The FTIR spectra of PHB, PBAT, PHB/PBAT blend, and $\mathrm{PHB} / \mathrm{PBAT} /$ stearate- $\mathrm{Zn}_{3} \mathrm{Al} \mathrm{LDH}$ nanocomposites are shown in Figure 5. The $\mathrm{C}=\mathrm{O}$ stretching bands of $\mathrm{PHB}$ are located at $1719 \mathrm{~cm}^{-1}$, with shoulders at about $1740 \mathrm{~cm}^{-1}$, which are representative of $\mathrm{PHB}$ crystalline and amorphous 


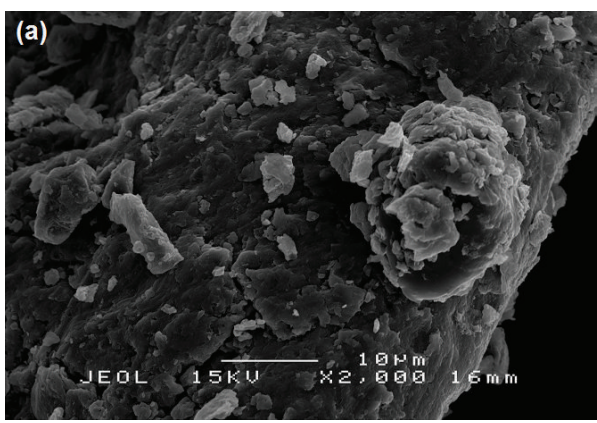

(a)

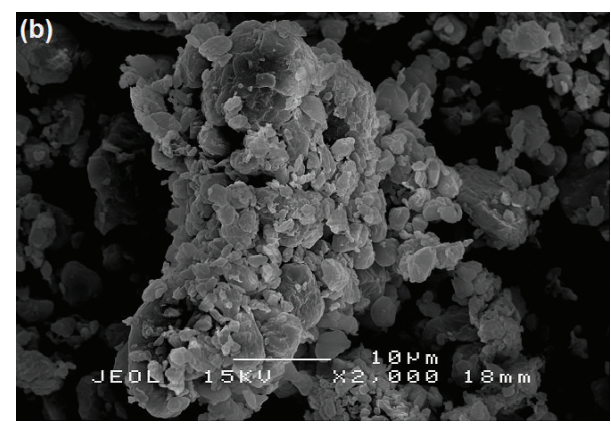

(b)

Figure 3: Scanning electron micrographs of (a) pristine $\mathrm{Zn}_{3} \mathrm{Al} \mathrm{LDH}$ and (b) stearate- $\mathrm{Zn}_{3} \mathrm{Al} \mathrm{LDH}$.

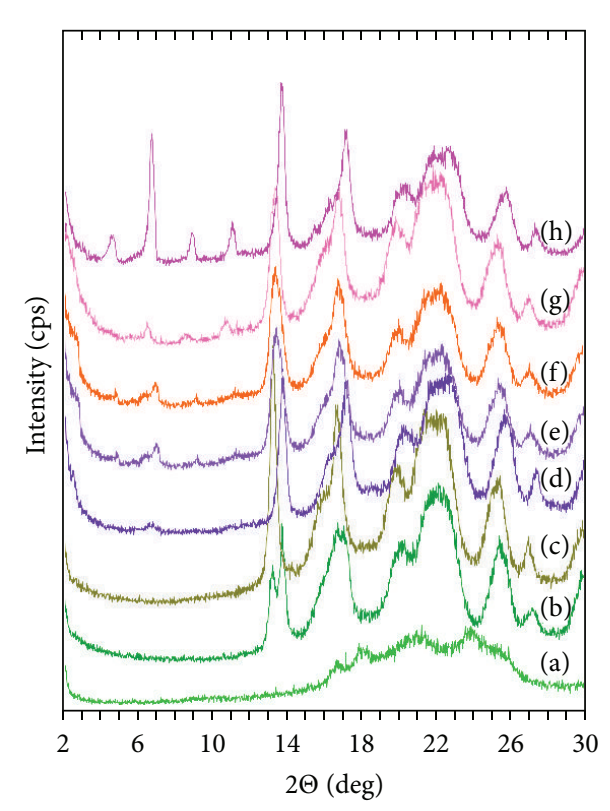

FIGURE 4: XRD pattern for (a) pure PBAT, (b) pure PHB, (c) PHB/PBAT blend, and nanocomposites of 1.0, 2.0, 3.0, 4.0, and $5 \mathrm{wt} \%$ of stearate- $\mathrm{Zn}_{3} \mathrm{Al} \mathrm{LDH}(\mathrm{d}-\mathrm{h})$.

zone. Meanwhile, the major peak observed was at $1712 \mathrm{~cm}^{-1}$ for $\mathrm{C}=\mathrm{O}$ stretching and $1475 \mathrm{~cm}^{-1}$ for aromatic $\mathrm{C}=\mathrm{C}$ stretching in PBAT chains. The spectra of PHB/PBAT blend and $\mathrm{PHB} / \mathrm{PBAT} /$ stearate $-\mathrm{Zn}_{3} \mathrm{Al} \mathrm{LDH}$ are consistent with the combination of PHB and PBAT. No major peak shifting and no new peak formation in the blend and nanocomposites spectra indicate that there is no strong interaction among $\mathrm{PHB}, \mathrm{PBAT}$, and stearate- $\mathrm{Zn}_{3} \mathrm{Al} \mathrm{LDH}$.

The tensile properties of $\mathrm{PHB}, \mathrm{PHB} / \mathrm{PBAT}$ blend, and PHB/PBAT/LDH nanocomposites were shown in Figures 6 and 7. The tensile strength of neat PHB was $25.54 \mathrm{MPa}$ and decreased to $23.10 \mathrm{MPa}$ with the addition of $10 \mathrm{wt} \%$ of PBAT. The tensile strength decreased again as the PBAT contents increase up to $50 \mathrm{wt} \%$. This observation was shown

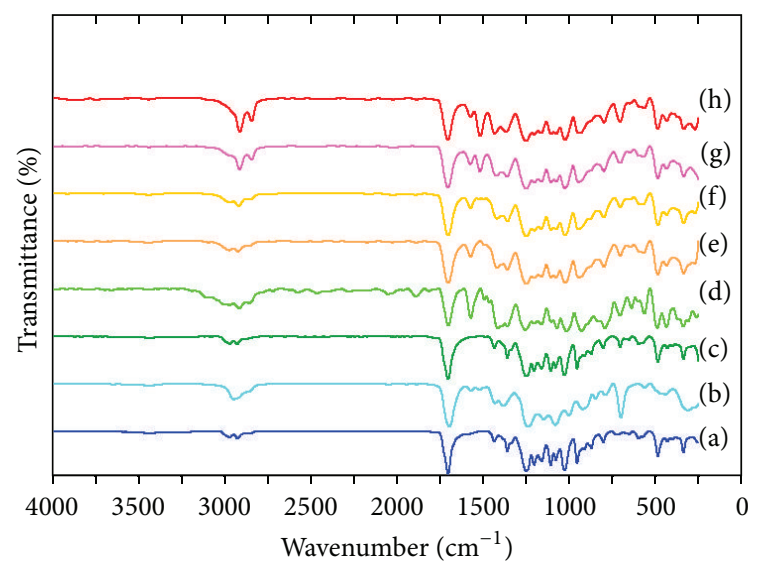

Figure 5: FTIR spectra for (a) pure PHB, (b) pure PBAT, (c) $\mathrm{PHB} / \mathrm{PBAT}$ blend, and nanocomposites of $\mathrm{PHB} / \mathrm{PBAT}$ with 1.0, 2.0, $3.0,4.0$, and $5 \mathrm{wt} \%$ of stearate- $\mathrm{Zn}_{3} \mathrm{Al} \mathrm{LDH}(\mathrm{d}-\mathrm{h})$.

in Figure 6(a). The effect of the amount of PBAT on tensile modulus and elongation at break for $\mathrm{PHB} / \mathrm{PBAT}$ composites were shown in Figures 6(b)-6(c), respectively. The tensile modulus and elongation at break increased with the loading of $10 \mathrm{wt} \%$ of PBAT content as compared to neat PHB. However, they were decreased thereafter as shown in Figures 6(b)-6(c). It was indicated that PBAT is able to enhance the elasticity of PHB. However, incorporation of more than $20 \mathrm{wt} \%$ PBAT content deteriorates the properties of the final products. As a result, $\mathrm{PHB} / \mathrm{PBAT}$ blend with $90 / 10$ ratio was chosen as the best ratio among others.

Figure 7 (a) shows that addition of $1 \mathrm{wt} \%$ of stearate $-\mathrm{Zn}_{3} \mathrm{Al}$ $\mathrm{LDH}$ into PHB/PBAT blend decreased the tensile strength to $19.62 \mathrm{MPa}$. Further increase in the stearate- $\mathrm{Zn}_{3} \mathrm{Al} \mathrm{LDH}$ decreased the tensile strength too as compared to that blend. The tensile strength for $2.0,3.0,4.0$, and $5.0 \mathrm{wt} \%$ of the $\mathrm{LDH}$ in polymer blend was $18.17,18.13,18.70$, and $19.60 \mathrm{MPa}$, respectively. It may be due to the extended aggregation of LDH layer into the blend matrix [31]. Figure 7(b) shows 


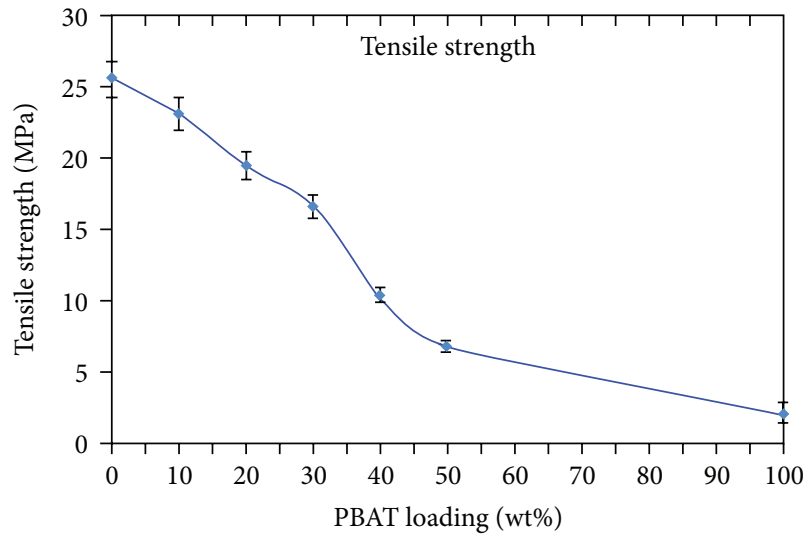

(a)

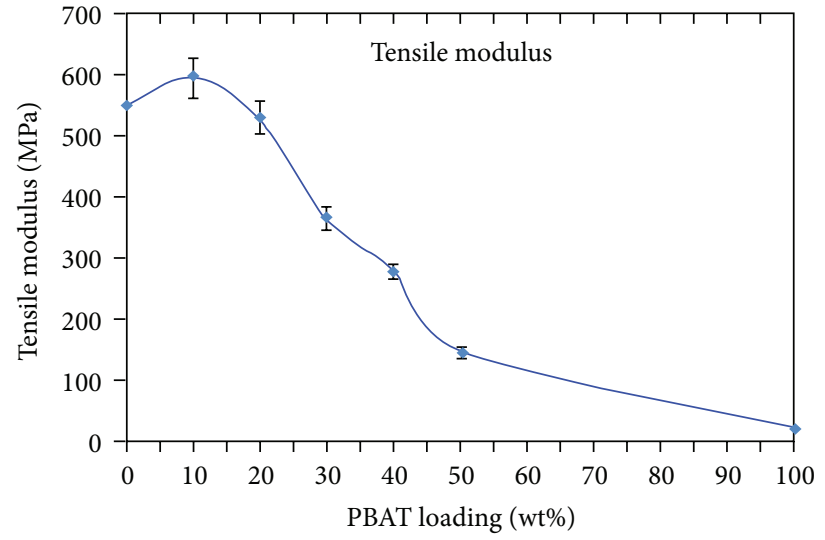

(b)

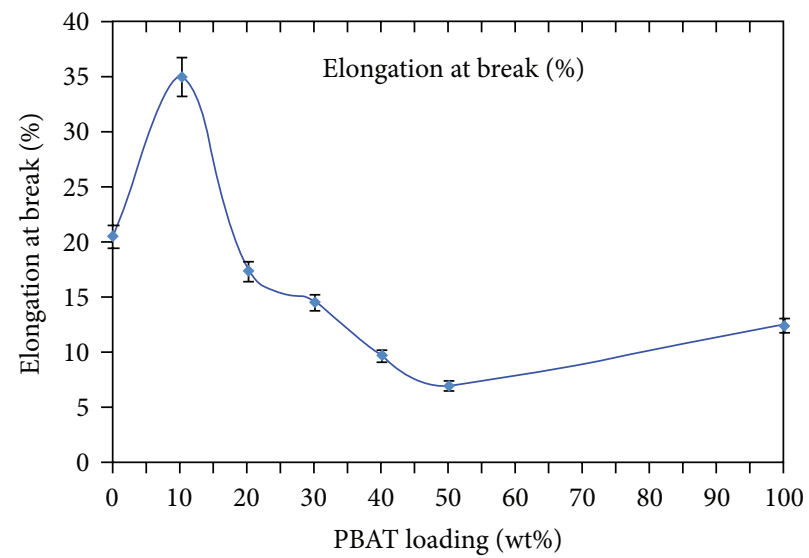

(c)

FIgURE 6: Tensile strength, tensile modulus, and elongation at break for PHB/PBAT blends (a-c).

that tensile modulus for nanocomposites also decreased as compared to the blend.

Adding $2.0 \mathrm{wt} \% \mathrm{LDH}$ into the polymer blend increased the elongation at break from $35.03 \%$ up to $54.58 \%$, with an improvement of $56 \%$ compared to that of the unfilled $\mathrm{PHB} / \mathrm{PBAT}$ blend in Figure $7(\mathrm{c})$. The significant increase in the flexibility of the nanocomposites may be due to the presence of the long chain hydrocarbon parts of stearate anions in the modified LDH that act as a plasticizer. The elongations at break for $1.0,3.0,4.0$, and $5.0 \mathrm{wt} \%$ nanocomposites were $38.55,25.15,10.10$, and $9.53 \%$, respectively. Decreasing trend of elongation at break can be observed after further addition of 3.0 to $5.0 \mathrm{wt} \%$ of $\mathrm{LDH}$. It may be due to the presence of large agglomerates which make the nanocomposites more brittle, decrease of elongation at break consequently.

Figure 8 shows SEM micrographs obtained from the tensile fracture surfaces of $\mathrm{PHB} / \mathrm{PBAT}$ blend and its nanocomposites containing $2.0 \mathrm{wt} \%$ of stearate- $\mathrm{Zn}_{3} \mathrm{Al} \mathrm{LDH}$. The image of the fractured surface of the PHB/PBAT blend sample (Figure 8(a)) shows a relatively compact solid surface indicating that the sample is brittle while the images of the $2.0 \mathrm{wt} \%$ nanocomposites (Figure 8(b)) show the rough and stretched surfaces which support the reduction of the rigidity of the samples.
The dispersion of stearate- $\mathrm{Zn}_{3} \mathrm{Al} \mathrm{LDH}$ in the composites was observed by TEM as shown in Figure 9 which presented $\mathrm{PHB} / \mathrm{PBAT}$ nanocomposites with $2.0 \mathrm{wt} \%$ loading of stearate- $\mathrm{Zn}_{3} \mathrm{Al} \mathrm{LDH}$. The dark parts of the micrograph were the stearate- $\mathrm{Zn}_{3} \mathrm{Al} \mathrm{LDH}$ while $\mathrm{PHB} / \mathrm{PBAT}$ matrix was represented by the clear parts. The TEM images of $2.0 \mathrm{wt} \%$ of $\mathrm{LDH} / \mathrm{PHB} / \mathrm{PBAT}$ nanocomposites confirmed that the intercalated silicate layers that were well distributed can be observed in PHB/PBAT as suggested by XRD diffractogram. The figures clearly show that the stack consists of several silicates layers, which indicated the formation of intercalated nanocomposites. The result supported by basal reflection in XRD diffractogram which confirmed the intercalated type of nanocomposites was formed. The TEM image revealed that the LDH layers are in intercalated but not well-ordered structure form and dominantly distributed in the PHB/PBAT matrix.

\section{Conclusions}

Stearate- $\mathrm{Zn}_{3} \mathrm{Al} \mathrm{LDH}$ was successfully prepared via ion exchange reaction. The presence of alkyl group in FTIR spectrum indicated that the stearate anions were 


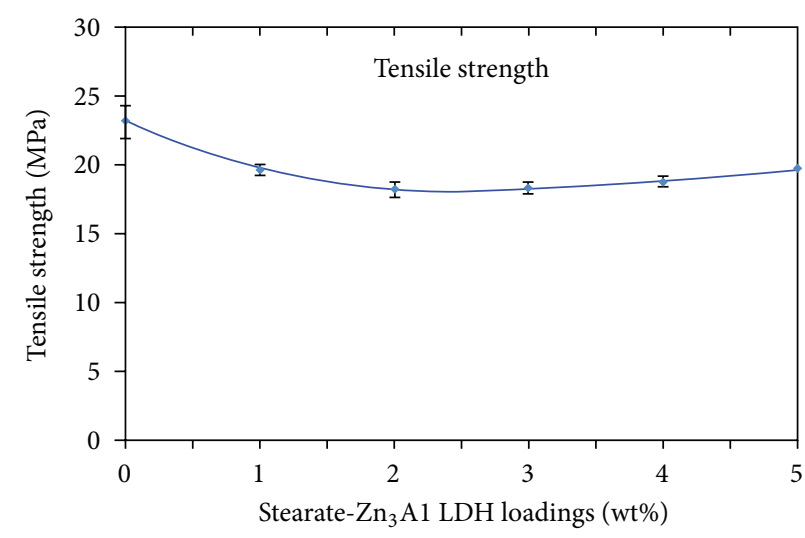

(a)

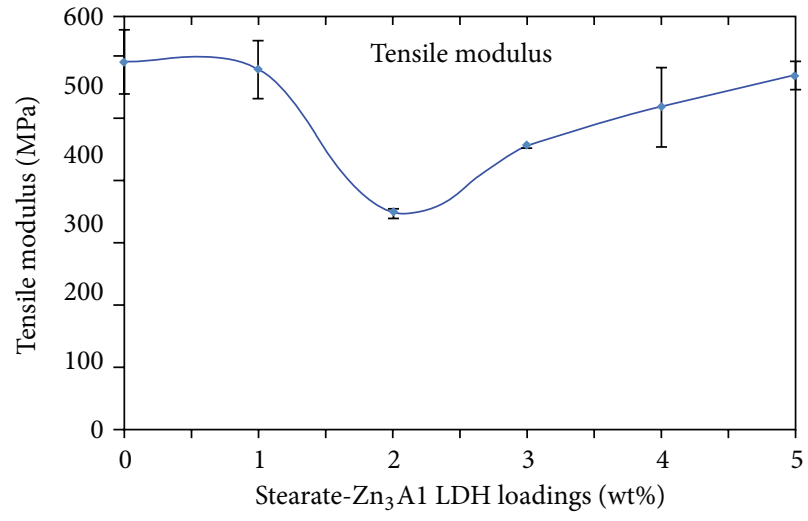

(b)

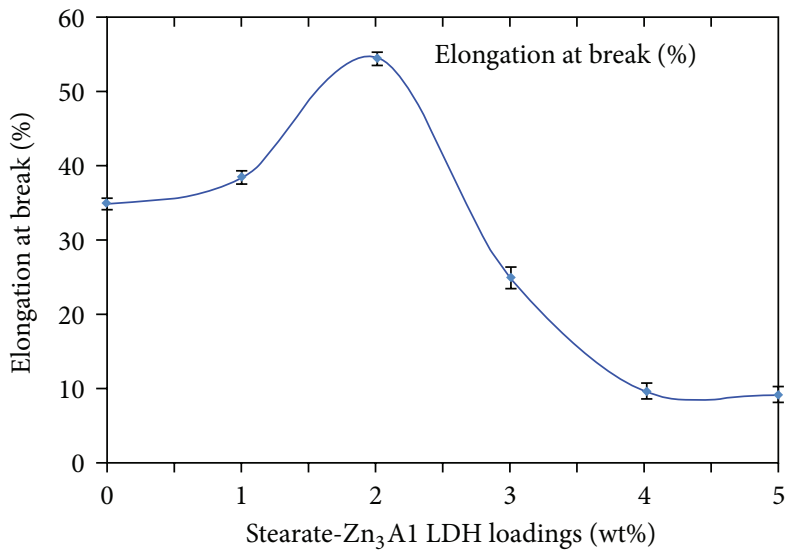

(c)

Figure 7: Tensile strength, tensile modulus, and elongation at break of PHB/PBAT blends with different stearate- $\mathrm{Zn}_{3} \mathrm{Al} \mathrm{LDH}$ content (a-c).

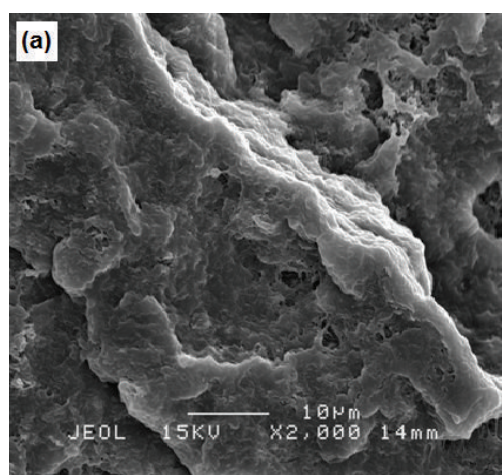

(a)

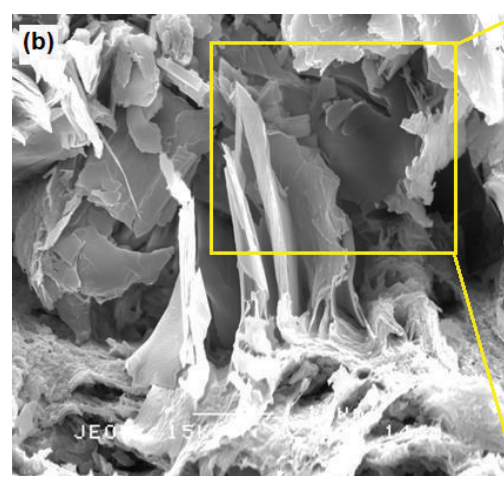

(b)

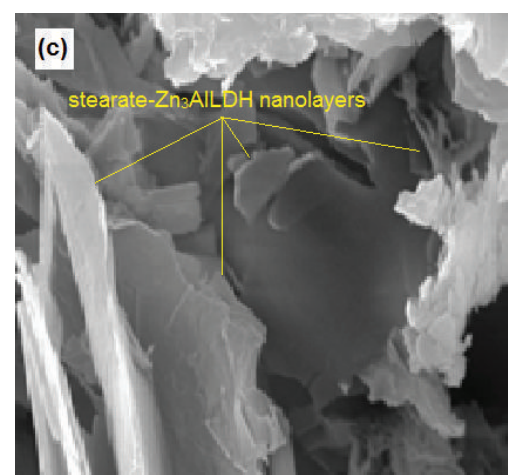

(c)

FIgURE 8: Scanning electron micrograph of (a) PHB/PBAT blend and (b, c) $2.0 \mathrm{wt} \%$ nanocomposites with low and high resolutions.

successfully intercalated into pristine LDH. The X-ray diffraction (XRD) patterns showed that the basal spacing of stearate- $\mathrm{Zn}_{3} \mathrm{Al} \mathrm{LDH}$ was higher than that of the pristine LDH. PHB/PBAT nanocomposites were successfully prepared with modified stearate- $\mathrm{Zn}_{3} \mathrm{Al} \mathrm{LDH}$ through solution casting method. The XRD and TEM showed that the $\mathrm{PHB} / \mathrm{PBAT} /$ stearate- $\mathrm{Zn}_{3} \mathrm{Al} \mathrm{LDH}$ formed intercalated structure as the modified stearate- $\mathrm{Zn}_{3} \mathrm{Al} \mathrm{LDH}$ content increased thus facilitating better compatibility of PHB/PBAT between the galleries of LDH. Mechanical analyses of nanocomposites showed that adding $2.0 \mathrm{wt} \%$ SLDH into the polymer blend increases the elongation at break from $35.03 \%$ up to $54.58 \%$, with an improvement of $56 \%$ compared to that of the neat PHB/PBAT blend. 

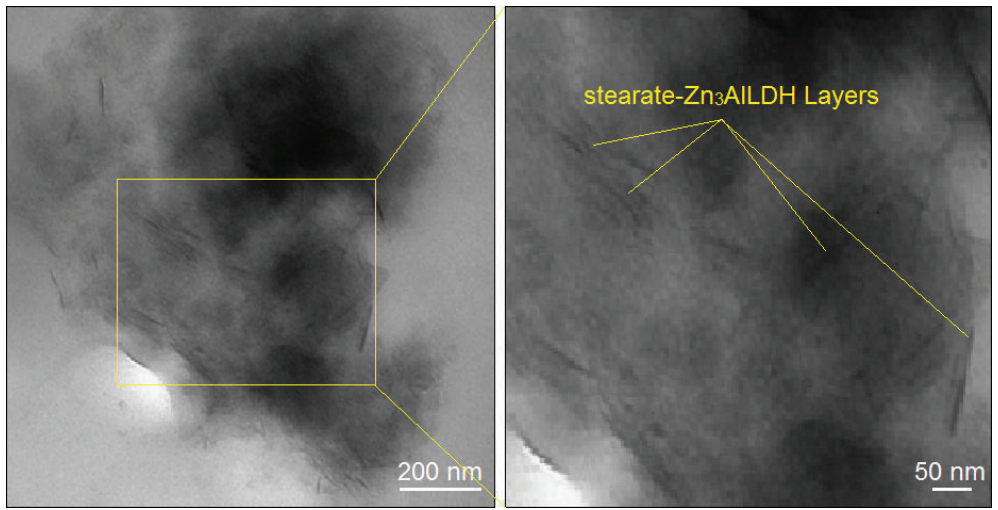

Figure 9: TEM micrographs of PHB/PBAT/2.0 wt\% stearate- $\mathrm{Zn}_{3} \mathrm{Al} \mathrm{LDH}$.

\section{Conflict of Interests}

The authors declare that there is no conflict of interests.

\section{Acknowledgments}

The authors would like to acknowledge the financial support from the Universiti Putra Malaysia (UPM) (RUGS Project no. 9199840). The authors are also grateful to the staff of the Department of Chemistry UPM and the Institute of Bioscience UPM for the technical assistance.

\section{References}

[1] W. S. Ahn, S. J. Park, and S. Y. Lee, "Production of poly(3hydroxybutyrate) by fed-batch culture of recombinant escherichia coli with a highly concentrated whey solution," Applied and Environmental Microbiology, vol. 66, no. 8, pp. 3624-3627, 2000.

[2] S. Godbole, S. Gote, M. Latkar, and T. Chakrabarti, "Preparation and characterization of biodegradable poly-3-hydroxybutyratestarch blend films," Bioresource Technology, vol. 86, no. 1, pp. 3337, 2003.

[3] L. H. Innocentini-Mei, J. R. Bartoli, and R. C. Baltieri, "Mechanical and thermal properties of poly(3-hydroxybutyrate) blends with starch and starch derivatives," Macromolecular Symposia, vol. 197, pp. 77-87, 2003.

[4] F. Gassner and A. J. Owen, "Physical properties of $\operatorname{poly}(\beta-$ hydroxybutyrate)-poly( $\varepsilon$-caprolactone) blends," Polymer, vol. 35, no. 10, pp. 2233-2236, 1994.

[5] D. Lovera, L. Márquez, V. Balsamo, A. Taddei, C. Castelli, and A. J. Müller, "Crystallization, morphology, and enzymatic degradation of polyhydroxybutyrate/polycaprolactone (PHB/PCL) blends," Macromolecular Chemistry and Physics, vol. 208, no. 9, pp. 924-937, 2007.

[6] K. Fukushima, C. Abbate, D. Tabuani, M. Gennari, and G. Camino, "Biodegradation of poly(lactic acid) and its nanocomposites," Polymer Degradation and Stability, vol. 94, no. 10, pp. 1646-1655, 2009.

[7] A. El-Hadi, R. Schnabel, E. Straube, G. Muller, and M. Riemschneider, "Effect of melt processing on crytallization behavior and rheology of poly (3-hydroxybutyrate) (PHB) and its blends," Macromolecular Materials and Engineering, vol. 287, pp. 363-372, 2002.
[8] M. Eili, K. Shameli, N. A. Ibrahim, and W. M. Z. Wan Yunus, "Degradability enhancement of poly(lactic acid) by stearate$\mathrm{Zn}_{3} \mathrm{Al} \mathrm{LDH}$ nanolayers," International Journal of Molecular Sciences, vol. 13, pp. 7938-7951, 2012.

[9] M. Yamaguchi and K. Arakawa, "Control of structure and mechanical properties for binary blends of poly(3hydroxybutyrate) and cellulose derivative," Journal of Applied Polymer Science, vol. 103, no. 5, pp. 3447-3452, 2007.

[10] M. B. Ahmad, K. Shameli, W. M. Z. W. Yunus, N. A. Ibrahim, and M. Darroudi, "Synthesis and characterization of Silver/Clay/Starch bionanocomposites by green method," Australian Journal of Basic and Applied Sciences, vol. 4, no. 7, pp. 2158-2165, 2010.

[11] M. B. Ahmad, K. Shameli, M. Darroudi, W. M. Z. W. Yunus, and N. A. Ibrahim, "Synthesis and characterization of silver/clay nanocomposites by chemical reduction method," American Journal of Applied Sciences, vol. 6, no. 11, pp. 1909-1914, 2009.

[12] M. B. Ahmad, M. Y. Tay, K. Shameli, M. Z. Hussein, and J. J. Lim, "Green synthesis and characterization of silver/chitosan/polyethylene glycol nanocomposites without any reducing agent," International Journal of Molecular Sciences, vol. 12, no. 8, pp. 4872-4884, 2011.

[13] K. Shameli, M. B. Ahmad, S. D. Jazayeri, P. Shabanzadeh, P. Sangpour, and H. Jahangirian, "Investigation of antibacterial properties silver nanoparticles prepared via green method," Chemistry Central Journal, vol. 6, no. 1, pp. 1-10, 2012.

[14] K. Shameli, M. B. Ahmad, E. A. Jaffar Al-Mulla, N. A. Ibrahim, and P. Shabanzadeh, "Green biosynthesis of silver nanoparticles using Callicarpa maingayi stem bark extraction," Molecules, vol. 17, no. 7, pp. 8506-8517, 2012.

[15] K. Shameli, M. B. Ahmad, S. D. Jazayeri, and P. Shabanzadeh, "Synthesis and characterization of polyethylene glycol mediated silver nanoparticles by the green method," International Journal of Molecular Sciences, vol. 13, no. 6, pp. 6639-6650, 2012.

[16] K. Shameli, M. B. Ahmad, A. Zamanian et al., "Green biosynthesis of silver nanoparticles using Curcuma longa tuber powder," International Journal of Nanomedicine, vol. 7, pp. 5603-5610, 2012.

[17] M. B. Ahmad, J. J. Lim, K. Shameli, N. A. Ibrahim, and M. Y. Tay, "Synthesis of silver nanoparticles in chitosan, gelatin and chitosan/gelatin bionanocomposites by a chemical reducing agent and their characterization," Molecules, vol. 16, no. 9, pp. 7237-7248, 2011. 
[18] S. Srivastava and N. A. Kotov, "Composite Layer-by-Layer (LBL) assembly with inorganic nanoparticles and nanowires," Accounts of Chemical Research, vol. 41, no. 12, pp. 1831-1841, 2008.

[19] S. J. Ahmadi, Y. D. Huang, and W. Li, "Synthetic routes, properties and future applications of polymer-layered silicate nanocomposites," Journal of Materials Science, vol. 39, no. 6, pp. 1919-1925, 2004.

[20] T. Hibino and W. Jones, "New approach to the delamination of layered double hydroxides," Journal of Materials Chemistry, vol. 11, no. 5, pp. 1321-1323, 2001.

[21] S. H. Cypes, W. M. Saltzman, and E. P. Giannelis, "Organosilicate-polymer drug delivery systems: controlled release and enhanced mechanical properties," Journal of Controlled Release, vol. 90, no. 2, pp. 163-169, 2003.

[22] J. Zhu, F. M. Uhl, A. B. Morgan, and C. A. Wilkie, "Studies on the mechanism by which the formation of nanocomposites enhances thermal stability," Chemistry of Materials, vol. 13, no. 12, pp. 4649-4654, 2001.

[23] V. Bugatti, U. Costantino, G. Gorrasi, M. Nocchetti, L. Tammaro, and V. Vittoria, "Nano-hybrids incorporation into poly $(\varepsilon$ caprolactone) for multifunctional applications: mechanical and barrier properties," European Polymer Journal, vol. 46, no. 3, pp. 418-427, 2010.

[24] A. Szép, A. Szabó, N. Tóth, P. Anna, and G. Marosi, "Role of montmorillonite in flame retardancy of ethylene-vinyl acetate copolymer," Polymer Degradation and Stability, vol. 91, no. 3, pp. 593-599, 2006.

[25] F. R. Costa, A. Leuteritz, U. Wagenknecht, D. Jehnichen, L. Häußler, and G. Heinrich, "Intercalation of Mg-Al layered double hydroxide by anionic surfactants: preparation and characterization," Applied Clay Science, vol. 38, no. 3-4, pp. 153-164, 2008.

[26] E. Mahboobeh, W. M. Z. W. Yunus, Z. Hussein, M. Ahmad, and N. A. Ibrahim, "Flexibility improvement of poly(lactic acid) by stearate-modified layered double hydroxide," Journal of Applied Polymer Science, vol. 118, no. 2, pp. 1077-1083, 2010.

[27] Y. Ding, Z. Gui, J. Zhu, Y. Hu, and Z. Wang, "Exfoliated poly(methyl methacrylate)/MgFe-layered double hydroxide nanocomposites with small inorganic loading and enhanced properties," Materials Research Bulletin, vol. 43, no. 12, pp. 32123220, 2008.

[28] F. Leroux and J. Besse, "Polymer interleaved layered double hydroxide: a new emerging class of nanocomposites," Chemistry of Materials, vol. 13, no. 10, pp. 3507-3515, 2001.

[29] J. Liu, G. Chen, and J. Yang, "Preparation and characterization of poly(vinyl chloride)/layered double hydroxide nanocomposites with enhanced thermal stability," Polymer, vol. 49, no. 18, pp. 3923-3927, 2008.

[30] U. Costantino, F. Marmottini, M. Nocchetti, and R. Vivani, "New synthetic routes to hydrotalcite-like compoundscharacterisation and properties of the obtained materials," European Journal of Inorganic Chemistry, no. 10, pp. 1439-1446, 1998.

[31] H.-B. Hsueh and C.-Y. Chen, "Preparation and properties of LDHs/polyimide nanocomposites," Polymer, vol. 44, no. 4, pp. 1151-1161, 2003.

[32] R. M. Da Silva Moreira Thiré, L. C. Arruda, and L. S. Barreto, "Morphology and thermal properties of poly(3hydroxybutyrate-co-3-hydroxyvalerate)/attapulgite nanocomposites," Materials Research, vol. 14, no. 3, pp. 340-344, 2011. 

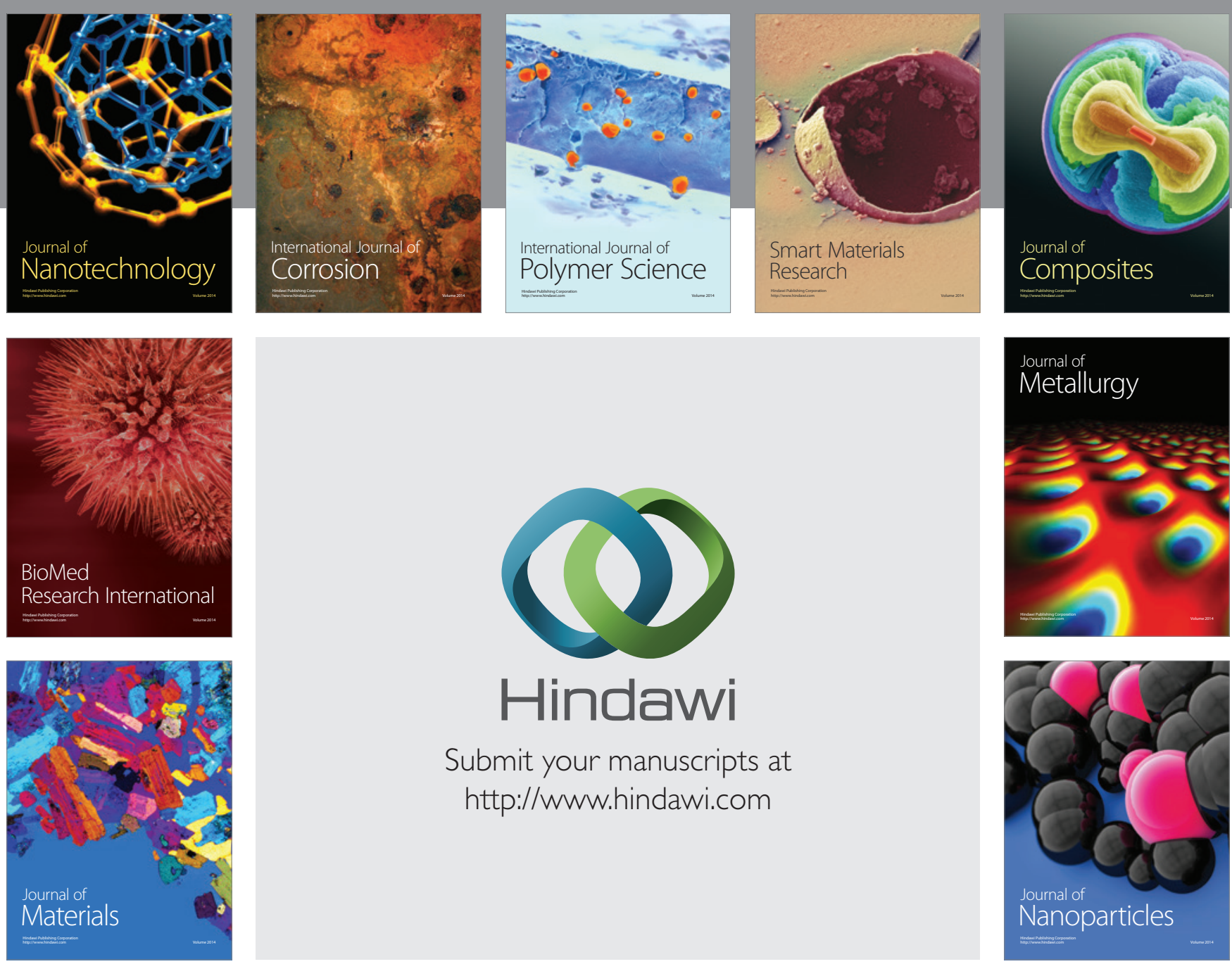

Submit your manuscripts at http://www.hindawi.com
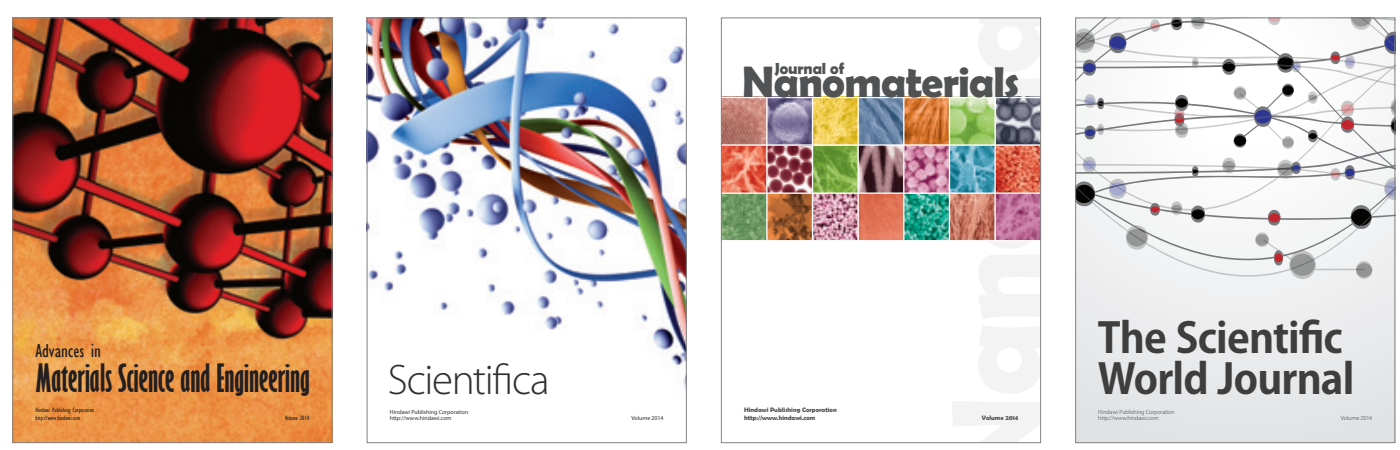

\section{The Scientific World Journal}
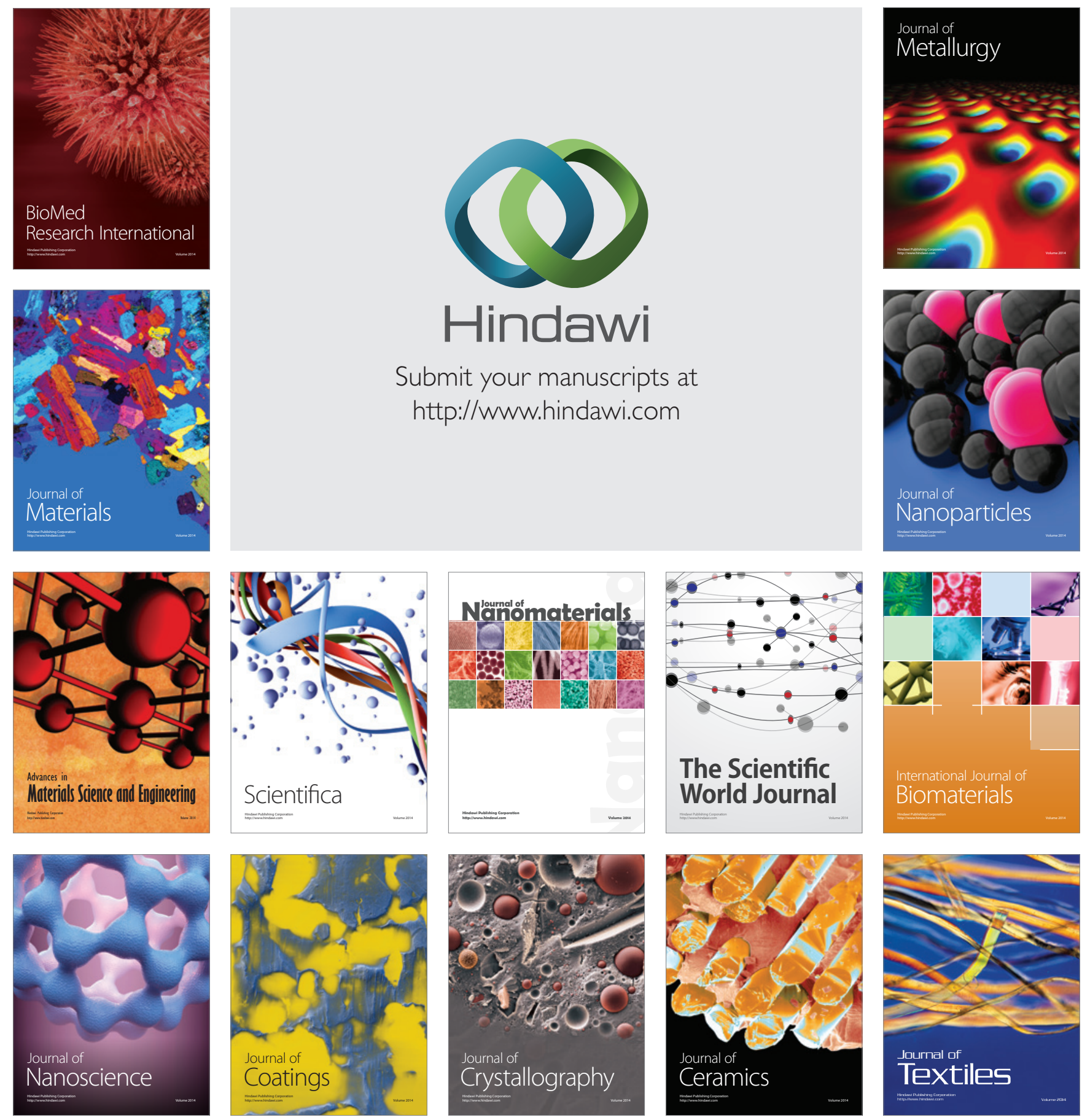